\title{
Artificial Intelligence in Primary Care: An Overview
}

\author{
Darius TURCIAN ${ }^{\mathrm{a}, 1}$ and Vasile STOICU-TIVADAR ${ }^{\mathrm{a}}$

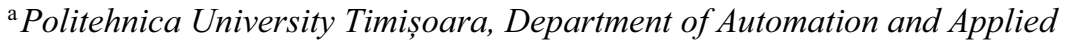 \\ Informatics, Timişoara, Romania
}

\begin{abstract}
With the increase in computing power and the development of numerous technological devices that facilitate remote work, the involvement of artificial intelligence in medicine has seen a significant increase to help the doctor make decisions and intervene in the medical process and telemedicine. In this paper, we gave an overview of the practical involvement of artificial intelligence through different support systems used in primary medicine or telemedicine and also identified the possibilities and opportunities for the development of new support systems for family medicine. Thus, we identified systems used for primary diagnosis, diagnosis of hypertension, early detection of heart abnormalities, detection of diabetes, support in the prescription process, helping clinicians in the daily workflow by providing certain answers to questions, treatment guidance, determining patient priority for treatment for SARS-CoV-2 infection or early detection of disease, support of artificial ventilation in medical emergency centers, remote support for treatments and medication.
\end{abstract}

Keywords. Artificial intelligence, primary care, family medicine

\section{Introduction}

One of the most important and emerging things today, in terms of technology is Artificial Intelligence (AI) that began to be used in a variety of domains. In all areas, the question is whether AI can be involved to improve and perfect the functioning of systems or help humans in taking decisions. In medicine, AI is seen as a great opportunity to increase or replace the limited processing power, to improve the identification accuracy of the diagnosis, to improve the efficiency in the doctor's workflow as well as patient scheduling, to increase productivity, to reduce medical errors, and to facilitate better patient monitoring. At the same time, there is a concern regarding what exactly AI can provide and also undermining trust in physicians. [1-4]

From the perspective of AI position as software with decision-making ability how it is presented in [3], AI has evolved from a rule-centric approach which is based on if-then rules to a data-centric approach which is based on capabilities to learn from data $[1,2]$.

Family medicine which is a clinical specialty oriented towards primary care is a field where AI can be used too to help humans in making decisions. The aims of this paper are to expose the current state of AI used in primary care and family medicine.

\footnotetext{
${ }^{1}$ Corresponding Author, Darius Turcian, Politehnica University Timişoara, Department of Automation and Applied Informatics, B019, Vasile Pârvan 2, Timișoara, Romania; E-mail: darius.turcian@upt.ro.
} 


\section{Methods}

To identify, evaluate and interpret the current state of AI used in family medicine and primary care, we performed a systematic search for specialized papers published starting with 2018, from the field of engineering and medicine. The main explorer was the IEEE Xplore database, and also National Center for Biotechnology Information (NCBI) including PMC and PubMed databases, Elsevier databases. The search strategy included terms related to AI and primary care such as artificial intelligence, machine learning, deep learning, family medicine, primary care, prediction, diagnosis, etc.

\section{Results}

\subsection{Searches}

Table 1 presents the search results based on the methods presented above.

Table 1. Search results

\begin{tabular}{lll}
\hline Keywords & Results description & Selections \\
\hline $\begin{array}{l}\text { Artificial intelligence in primary } \\
\text { care }\end{array}$ & $\begin{array}{l}\text { From the first 50 results, 17 matched the subject } \\
\text { and 3 were selected }\end{array}$ & {$[5],[6],[7]$} \\
$\begin{array}{l}\text { Machine learning in primary } \\
\text { care }\end{array}$ & $\begin{array}{l}\text { From the first 50 results, } 12 \text { matched the subject } \\
\text { and 3 were selected }\end{array}$ & {$[8],[9],[10]$} \\
$\begin{array}{l}\text { Decision support system in } \\
\text { primary care }\end{array}$ & $\begin{array}{l}\text { From the first 20 results, 5 matched the subject } \\
\text { and 2 were selected }\end{array}$ & {$[11],[12]$} \\
Primary diagnosis & $\begin{array}{l}\text { From the first 20 results, 8 matched the subject } \\
\text { and 2 were selected }\end{array}$ & {$[13],[14]$} \\
COVID-19 & $\begin{array}{l}\text { From the first 15 results, 4 matched the subject } \\
\text { and 2 were selected }\end{array}$ & {$[15],[16]$} \\
\hline
\end{tabular}

After the first selection for those papers which matched the subject based on the abstract study, we selected a subset of the found papers, based on the date of publication and the importance of systems for primary care.

\subsection{Practical implications}

In table 2 are presented AI systems and their techniques / methods used and the accuracy for each of them.

Table 2. AI systems developed for primary care and telemedicine

\begin{tabular}{|c|c|c|c|}
\hline System & Technique/ Algorithm & Accuracy & Reference \\
\hline ML model to predict hypertension & $\begin{array}{l}\text { Three-layer Artificial Neural } \\
\text { Network (ANN) }\end{array}$ & $82 \%$ & {$[8]$} \\
\hline $\begin{array}{l}\text { Clinical Decision Support System (CDSS) } \\
\text { for generating alerts during medication } \\
\text { prescribing }\end{array}$ & Oracle Data Warehouse & Unknown & {$[11]$} \\
\hline $\begin{array}{l}\text { ML system for primary diagnosis from chief } \\
\text { complaints }\end{array}$ & $\begin{array}{l}\text { Naïve Bayes and Random } \\
\text { Forest classifiers }\end{array}$ & $\begin{array}{l}66.1 \%- \\
77.7 \%\end{array}$ & [13] \\
\hline Q\&A system (called AI-Q) & $\begin{array}{l}\text { DL with Natural Language } \\
\text { Processing (NLP) operations }\end{array}$ & Low & {$[6]$} \\
\hline $\begin{array}{l}\text { CDSS used for guidance the patient's } \\
\text { treatment }\end{array}$ & Rules-based & Unknown & {$[12]$} \\
\hline $\begin{array}{l}\text { ML system used to determine the priority of } \\
\text { patients for treatment for Covid- } 19\end{array}$ & $\begin{array}{l}\text { Convolutional Neural } \\
\text { Network }(\mathrm{CNN}) \text { model }\end{array}$ & $96.5 \%$ & {$[15]$} \\
\hline $\begin{array}{l}\text { CDSS used for an early detection of the } \\
\text { coronavirus disease }\end{array}$ & DL model & $92.5 \%$ & {$[16]$} \\
\hline
\end{tabular}




\begin{tabular}{|c|c|c|c|}
\hline $\begin{array}{l}\text { CDSS system which use IoT devices in ICU } \\
\text { centers to provide alerts regarding } \\
\text { ventilation therapy }\end{array}$ & ML algorithms & $\begin{array}{l}97.1 \%- \\
97.93 \%\end{array}$ & [9] \\
\hline $\begin{array}{l}\text { Portable AI system used for early detections } \\
\text { of heart abnormalities }\end{array}$ & CNN algorithm & $\begin{array}{l}75.2 \%- \\
97 \%\end{array}$ & [14] \\
\hline $\begin{array}{l}\text { Mobile application which offers on-line } \\
\text { information regarding treatments and drugs }\end{array}$ & ML and Data Mining & Unknown & {$[7]$} \\
\hline ML system that predicts diabetes & $\begin{array}{l}\text { ML algorithms based on Big } \\
\text { Data analysis }\end{array}$ & $58 \%-82 \%$ & {$[10]$} \\
\hline
\end{tabular}

\section{Discussion}

From the analysis of the presented systems, we noticed a great potential for improvement comparing with human decision only, both in terms of execution time and the limitation of human errors. In most cases the methods used are focused on the "data-centric approach" using ML and DL algorithms with ANN and CNN methods.

$\mathrm{AI}$ is increasingly used in primary medicine and implicitly this will revolutionize family medicine. In this sense, an important step is represented by CDSS that have the ability to predict a certain diagnosis. For diseases that require CT scans, we noticed that ML and DL analyzes can be used in a very precise way on X-Ray images to highlight a diagnosis and its severity. We also noticed that for monitoring patients, ML algorithms can be used to generate different alerts depending on the patient's health status. Then another important factor is the ability to create smart mobile or web applications based on artificial intelligence, to help the family doctor make decisions and prescribe drugs or give priority to patients with more serious conditions. Another step is to identify the possibilities of creating AI-based CDSS to diagnose and provide treatment for most conditions often present in a family doctor's office.

The main concern of AI systems is still an accurate prediction. On the other hand, there is a need for external validation, integration into clinical workflow, approaching special cases, or facing the clinicians' reticence. Then the ethical aspects should be considered for the possible decisions errors or medical malpractice. An ethical problem is that $\mathrm{AI}$ has the potential to change the dynamic relationship between patient-clinician by introducing a new factor of trust - AI.

\section{Conclusions}

In this paper, we have created an overview of the systems based on artificial intelligence, that are used in primary care and not only, but also that offer viable solutions for telemedicine and the possibility of working remotely with the family doctor with his patients.

A further study will be necessary to evaluate and identify a better technique that can be used as part of the CDSS in family medicine together with NLP in order to create intelligent systems. Also, a good way to improve these types of systems is to implement a global place in Cloud to store all the public EMR of patients as a dataset that can be used for training the ML systems, to become a more efficient training model.

The system used in Thailand for predicting diagnosis based on a text input is a great inspiration and together with AI-Q system, the prioritization system leads us to think about the development of an intelligent CDSS used in family medicine, on the one hand, 
to give priority to patients and provide them with a solution to communicate with the system that proposes a diagnosis, validated by the doctor, proposes a treatment, validated by the doctor and on the other hand, solves many tasks in the doctor's office.

Future research will follow these aspects and will look for solutions not only to obtain greater accuracy but also to reduce the limitations and concerns presented in this paper regarding AI.

\section{References}

[1] Kaul V, Enslin S, Gross SA. History of artificial intelligence in medicine. Gastrointestinal Endoscopy. 2020 Oct;92(4):807-12.

[2] Liyanage H, Liaw S-T, Jonnagaddala J, Schreiber R, Kuziemsky C, Terry AL, et al. Artificial Intelligence in Primary Health Care: Perceptions, Issues, and Challenges: Primary Health Care Informatics Working Group Contribution to the Yearbook of Medical Informatics 2019. Yearb Med Inform. 2019 Aug;28(01):041-6.

[3] Mistry P. Artificial intelligence in primary care. Br J Gen Pract. 2019 Sep;69(686):422-3.

[4] Topol EJ. High-performance medicine: the convergence of human and artificial intelligence. Nat Med. 2019 Jan;25(1):44-56.

[5] Tsoi KKF. Application of Artificial Intelligence on a Symptom Diagnostic Platform for Telemedicine A Pilot Case Study. In: 2019 IEEE International Conference on Systems, Man and Cybernetics (SMC). Bari, Italy: IEEE; 2019. p. 806-13.

[6] Hanada E, Wada K, Oda K, Nishi K, Kawazoe K. Practical use of Artificial Intelligence for Clinical Staff Other than Physicians. In: 2018 IEEE 8th International Conference on Consumer Electronics - Berlin (ICCE-Berlin). Berlin: IEEE; 2018. p. 1-4.

[7] Liu W, Yuhang L, Lingling P, Na C. Design and Implementation of Family Doctor App on Android Platform. In: 2018 9th International Conference on Information Technology in Medicine and Education (ITME). Hangzhou: IEEE; 2018. p. 128-32.

[8] LaFreniere D, Zulkernine F, Barber D, Martin K. Using machine learning to predict hypertension from a clinical dataset. In: 2016 IEEE Symposium Series on Computational Intelligence (SSCI). Athens, Greece: IEEE; 2016. p. 1-7.

[9] Rehm GB, Woo SH, Chen XL, Kuhn BT, Cortes-Puch I, Anderson NR, et al. Leveraging IoTs and Machine Learning for Patient Diagnosis and Ventilation Management in the Intensive Care Unit. IEEE Pervasive Comput. 2020 Jul 1;19(3):68-78.

[10] Ahmed H, Younis EMG, Ali AA. Predicting Diabetes using Distributed Machine Learning based on Apache Spark*. In: 2020 International Conference on Innovative Trends in Communication and Computer Engineering (ITCE). Aswan, Egypt: IEEE; 2020. p. 44-9.

[11] Albahly MS, Seliaman ME. Evaluation of the impact of Clinical Decision Support Systems: Descriptive Analytics. In: 2020 2nd International Conference on Computer and Information Sciences (ICCIS). Sakaka, Saudi Arabia: IEEE; 2020. p. 1-5.

[12] Duarte de Almeida JR, Oliveira JL. GenericCDSS - A Generic Clinical Decision Support System. In: 2019 IEEE 32nd International Symposium on Computer-Based Medical Systems (CBMS). Cordoba, Spain: IEEE; 2019. p. 186-91.

[13] Pettakorn S, Sutantayawalee V, Thammasudjarit R. Primary Diagnosis Prediction from Chief Complaints. In: 2020 17th International Joint Conference on Computer Science and Software Engineering (JCSSE). Bangkok, Thailand: IEEE; 2020. p. 145-9.

[14] Singh KK, Singh SS. An Artificial Intelligence based mobile solution for early detection of valvular heart diseases. In: 2019 IEEE International Conference on Electronics, Computing and Communication Technologies (CONECCT). Bangalore, India: IEEE; 2019. p. 1-5.

[15] Rahim A, Kurniawan M, Kusrini. Machine Learning Based Decision Support System for Determining the Priority of Covid-19 Patients. In: 2020 3rd International Conference on Information and Communications Technology (ICOIACT). Yogyakarta, Indonesia: IEEE; 2020. p. 319-24.

[16] Qjidaa M, Ben-fares A, Mechbal Y, Amakdouf H, Maaroufi M, Alami B, et al. Development of a clinical decision support system for the early detection of COVID-19 using deep learning based on chest radiographic images. In: 2020 International Conference on Intelligent Systems and Computer Vision (ISCV). Fez, Morocco: IEEE; 2020. p. 1-6. 